\title{
IMMUNOHISTOCHEMICAL ANALYSIS OF MESOTHELIN IN EPITHELIAL TUMOURS OF OVARY
}

\author{
Farhana Chathoth Kannoli ${ }^{1}$, Shanthala P. R2 ${ }^{2}$ Prema Saldanha ${ }^{3}$
}

1 Postgraduate Student, Department of Pathology, Yenepoya Medical College, Yenepoya University, Deralakatte, Mangalore. ${ }^{2}$ Associate Professor, Department of Pathology, Yenepoya Medical College, Yenepoya University, Deralakatte, Mangalore. 3Professor, Department of Pathology, Yenepoya Medical College, Yenepoya University, Deralakatte, Mangalore.

\section{ABSTRACT}

\section{BACKGROUND}

Mesothelin is a cell surface glycoprotein expressed normally on mesothelial cells. The limited expression of mesothelin in normal tissues and high expression in some tumours has made it a good target for tumour-specific antibody-based therapies and other similar approaches.

The aim of the present study was to observe the expression status of mesothelin in ovarian epithelial tumours and to analyse the relationship between mesothelin expression status of malignant ovarian epithelial tumours and clinicopathological parameters like histologic type, grade and chemotherapy status.

\section{MATERIALS AND METHODS}

The retrospective study included 30 histologically diagnosed cases of ovarian epithelial tumours. The clinical and pathological findings were recorded. Immunohistochemical (IHC) study was performed with marker mesothelin on all cases and the findings were independently interpreted by two observers.

\section{RESULTS}

The study included 15 cases of benign and 15 cases of malignant epithelial tumours. The 15 benign cases were in age range of 18 62 years with only $7 \%$ being bilateral. There was near equal incidence of serous and mucinous types. The mesothelin positivity was seen in cells of all benign tumours (serous and mucinous cystadenomas). The 15 malignant ovarian tumours were found in women of age range 25 - 70 years. Most (73\%) of the tumours were bilateral. There were predominantly serous carcinomas (86\%) and few mucinous (14\%). IHC study revealed $13 / 13$ cases (100\%) showing diffuse mesothelin positivity in serous carcinomas, while all the mucinous carcinomas were negative.

\section{CONCLUSION}

Mesothelin is expressed highly in serous carcinomas. This suggests that therapy using mesothelin as target may be of possible use in the management of malignant serous tumours.

\section{KEYWORDS}

Mesothelin, Ovarian Epithelial Tumour, Cystadenoma, Carcinoma.

HOW TO CITE THIS ARTICLE: Kannoli FC, Shanthala PR, Saldanha P. Immunohistochemical analysis of mesothelin in epithelial tumours of ovary. J. Evolution Med. Dent. Sci. 2016;5(98):7192-7195, DOI: 10.14260/jemds/2016/1627

\begin{abstract}
BACKGROUND
Ovarian cancer is the seventh most common cancer in women as per global incidence.(1) In India, there is an increasing incidence of ovarian cancer with the trends of $3^{\text {rd }}$ or $4^{\text {th }}$ most common cancer in women.(2) According to WHO, primary ovarian tumours are classified into broad categories of epithelial tumours, mesenchymal tumours, mixed epithelial and mesenchymal tumours, sex cord stromal tumours, mixed sex cord stromal tumours, germ cell tumours, germ cell sex cord stromal tumours.(3) About $50 \%$ of all ovarian tumours are epithelial tumours, of which $90 \%$ are found to be malignant. The Epithelial Ovarian Cancers (EOC) include the histological type serous, mucinous, endometrioid, clear cell, transitional/Brenner and mixed. Serous carcinomas (87\%) are the commonest malignant ovarian epithelial tumours. ${ }^{(4)}$

In view of increased risk of ovarian cancer mortality,(1) newer therapeutic approaches are in research. The understanding of the biology and pathogenesis of ovarian cancer has led to many studies focusing on finding novel prognostic and predictive biomarkers of clinical use. Several biomarkers have been suggested, of which mesothelin is found to be one such marker of clinical significance. The mesothelial lining of pleura, peritoneum and pericardium express mesothelin a cell surface glycoprotein. In addition over expression of mesothelin is observed in various malignancies like malignant mesothelioma, ovarian cancer and pancreatic cancer.(5) The present study was done to observe the mesothelin expression status in benign and malignant ovarian epithelial tumours.
\end{abstract}

Financial or Other, Competing Interest: None.

Submission 26-10-2016, Peer Review 25-11-2016,

Acceptance 01-12-2016, Published 08-12-2016.

Corresponding Author:

Dr. Farhana Chathoth Kannoli,

Room No. T4, Silver Sands Apartment,

Behind Yenepoya Medical College,

Deralakatte-575018, Mangalore, Karnataka.

E-mail: drfarhanack19@gmail.com

DOI: $10.14260 /$ jemds/2016/1627

\section{MATERIALS AND METHODS}

A retrospective study was done on thirty histopathologically diagnosed cases of ovarian epithelial tumours. Clinical data was recorded from the files. The Haematoxylin and Eosin stained slides were retrieved from the archives of the Department of Pathology and histomorphological features were analysed. One formalin fixed paraffin-embedded tissue block of each case was selected and standard $4 \mu \mathrm{m}$ sections were subjected to immunohistochemical (IHC) study. Primary antibody to mesothelin (EP140 rabbit monoclonal antibody, 
Pathnsitu) was used. The PolyExcel HRP (Non-biotin, micropolymer based) DAB detection system was used with adequate positive and negative controls. The membrane and cytoplasm of the tumour cells showing brown colour was considered positive. Results were interpreted by 2 observers with a consensus reached regarding any discrepancy.

\section{RESULTS}

The present study includes thirty cases of ovarian epithelial tumours, of which 15 were benign and 15 were malignant.

\section{Benign Ovarian Epithelial Tumours}

The 15 benign cases observed were in age range of 18 - 62 yrs. Most of these (93\%) were unilateral and left sided (64\%). Tumour size ranged from $2.5-20 \mathrm{~cm}$. Grossly, all the tumours were cystic with $73.3 \%(11 / 15)$ presenting as unilocular cysts. On histopathology $53.3 \% \quad(8 / 15)$ were mucinous cystadenomas and the rest were serous cystadenomas. Immunohistochemical studies revealed positive mesothelin expression in all 15 benign epithelial tumours of both serous and mucinous types (Figure 1 and Table 1).

\section{Malignant Ovarian Epithelial Tumours}

The 15 malignant ovarian epithelial tumours were found in an age range of 25 to 70 yrs. There were 11 cases (73.3\%) of bilateral tumours. Grossly, the size of tumours ranged from 3 $13 \mathrm{cms}$. Among these $73.3 \%(11 / 15)$ of cases were solid cystic, $13.3 \%(2 / 15)$ were predominantly solid and $13.3 \%(2 / 15)$ were predominantly cystic. The histopathological types included $86 \%(13 / 15)$ - serous carcinomas and 14\% (2/15) mucinous carcinomas. The other histological types were not observed. There were $46.6 \%$ (7/15) tumours, which were of post-neoadjuvant chemotherapy status. CA-125 levels were found to be in a range of $20-7740 \mathrm{IU} / \mathrm{mL}$ in serous carcinomas and were in the range of $6-8 \mathrm{IU} / \mathrm{mL}$ in mucinous carcinomas. Immunohistochemical study done with mesothelin antibody revealed $100 \%(13 / 13)$ positivity in serous carcinomas of all grades and also in residual tumour of post-chemotherapy cases, while the mucinous carcinomas $(2 / 2)$ were negative (Figure 2 and Table 1).

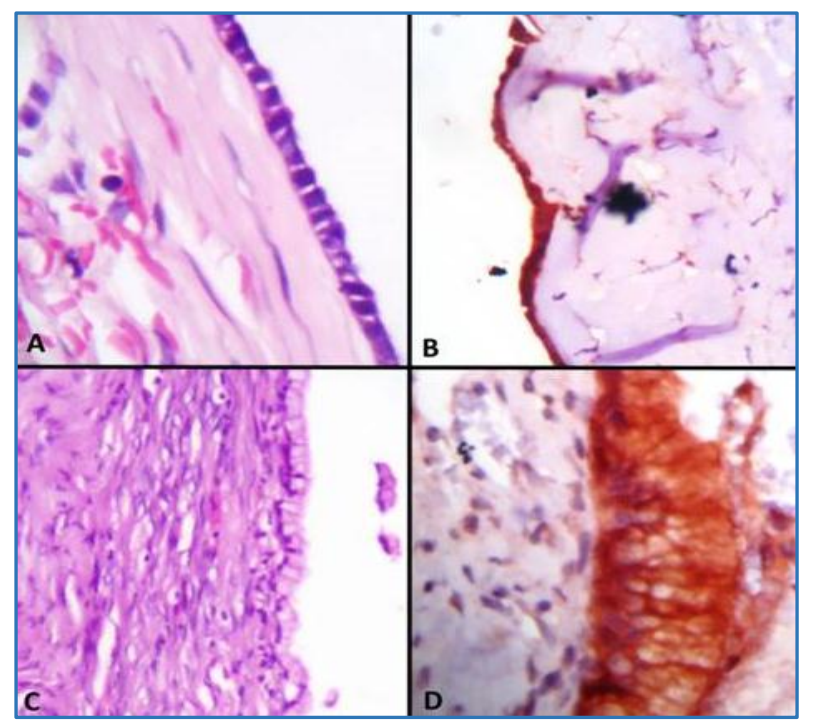

Figure 1. A - Serous Cystadenoma: H \& E, 10X,

$B$ - Serous Cystadenoma, Mesothelin Positive IHC10 X, $C$ - Mucinous Cystadenoma: H \& E, 10X,

D - Mucinous Cystadenoma, Mesothelin Positive IHC10 X

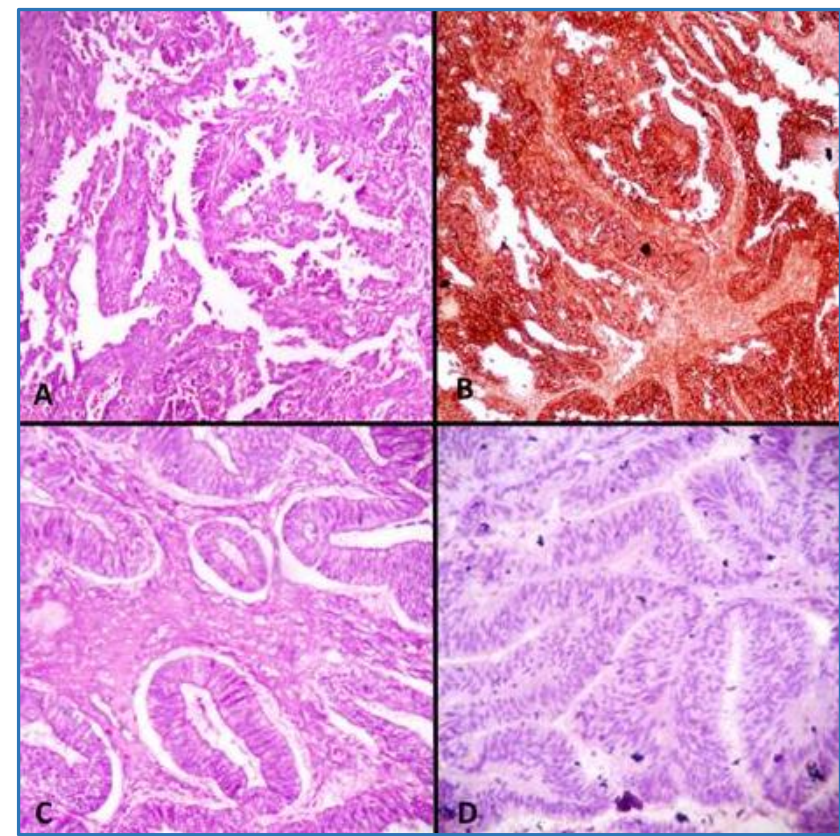

Figure 2. A - Serous Carcinoma H \& E - 10X,

$B$ - Serous Carcinoma, Mesothelin Diffuse Positive IHC -10X,

C - Mucinous Carcinoma H \& E 40X,

D-Mucinous Carcinoma, Mesothelin Negative IHC - 40X

\begin{tabular}{|c|c|c|c|c|}
\hline Histology & Type & $\begin{array}{c}\text { No. of } \\
\text { Cases }\end{array}$ & $\begin{array}{c}\text { Mesothelin } \\
\text { +ve }\end{array}$ & $\begin{array}{c}\text { Mesothelin } \\
\text {-ve }\end{array}$ \\
\hline \multirow{2}{*}{ Serous } & Benign & 07 & 07 & 0 \\
\cline { 2 - 5 } & Malignant & 13 & 13 & 0 \\
\hline \multirow{2}{*}{ Mucinous } & Benign & 08 & 08 & 0 \\
\cline { 2 - 5 } & Malignant & 02 & 0 & 02 \\
\hline \multicolumn{6}{|c|}{ Table 1. Epithelial Tumours and Mesothelin Expression } \\
\hline
\end{tabular}

\section{DISCUSSION}

The suggested screening tests for epithelial ovarian cancers include transvaginal sonography, pelvic examination and CA125 measurements.(6) Serum CA-125 is the commonly used biomarker for aiding in the diagnosis, monitoring and also for the differential diagnosis of ovarian cancers in context of other pelvic masses. The increase in serum CA-125 levels in postsurgery cases of EOCs is found to be suggestive of recurrence. However, CA-125 testing suffers low specificity as elevated levels may also be seen in many benign abdominal diseases. Many studies done in the recent past has shown CA-125 levels are of limited use in mucinous tumours. $(7,8)$ The CA-125 levels are found to be $99 \%$ specific in apparently healthy postmenopausal women, while are less specific in premenopausal women. (9) Huang et al observed higher serum CA-125 levels in serous, endometrioid and undifferentiated histological types than in the mucinous and the clear cell types of ovarian tumours. (8) Similarly, in our study also we have observed that the CA- 125 was in a range of $20-7740 \mathrm{IU} / \mathrm{mL}$ in serous carcinomas, while it was in the range of $6-8 \mathrm{IU} / \mathrm{mL}$ in mucinous carcinomas. There has been a search for more specific and/or sensitive tumour marker assay that can complement CA-125.

Mesothelin is a $40 \mathrm{kDa}$ glycosyl-phosphatidylinositol anchored cell surface glycoprotein expressed normally on mesothelial lining of pleura, peritoneum and pericardium. The gene mesothelin encodes, a $71 \mathrm{KDa}$ precursor protein, which is cleaved proteolytically into $40 \mathrm{KDa}$ - mesothelin and $31 \mathrm{KDa}$ 
- megakaryocyte potentiating factor secreted into blood.(10) Overexpression of mesothelin is observed in various malignancies like non-mucinous ovarian carcinomas and adenocarcinomas arising from the pancreaticobiliary tract, endometrium and lungs.(11) Thus, mesothelin is found to be an emerging marker for aiding in diagnosis and prognosis of ovarian carcinomas. The serum and urinary mesothelin levels have been studied in context of ovarian epithelial tumours. The studies related to mesothelin expression in the tissues using immunohistochemical methods are few. The limited expression of mesothelin in normal tissues and high expression in some tumours has made it a good target for tumour-specific antibody-based therapies and other similar approaches.(12)

The concept of carcinogenesis of epithelial ovarian tumours has been evolving with updates to understand the morphological heterogeneity of these tumours. In the initial concepts of ovarian carcinogenesis described, the ovarian surface epithelium (Mesothelium) undergoes metaplasia resulting in the development of the different epithelial tumours. Later, another theory proposed that the mesothelium invaginates into the underlying ovarian stroma forming "cortical inclusion cysts." Under the influence of local factors, the mesothelium of these cysts undergoes metaplasia resulting in Mullerian-type epithelium, which later undergoes malignant transformation resulting in epithelial ovarian cancer.(13) Ovarian Surface Epithelium (OSE) is lined by single layer of peritoneal cells and has also been described as a modified mesothelium. These cells are mesodermally derived and are not purely epithelial cells. Hence, the cells are immunoreactive for some of the epithelial and mesothelial cell markers. (14)

The few studies done in recent past on mesothelin expression in ovarian tumours and present study suggest that ovarian epithelial tumours show variable mesothelin expression. The present study revealed mesothelin positivity $(100 \%)$ in all benign and malignant serous tumours. In a study by Frierson et al on mesothelin expression in common carcinomas observed mesothelin immunoreactivity to be highest in cancers of ovary (Serous papillary, endometrioid and undifferentiated types) and pancreas.(15) The study done by Ornandez et al revealed high mesothelin expression in nonmucinous tumours of ovary (Nearly $100 \%$ in serous, endometrioid and transitional cell tumours, some of the clear cell tumours).(16) In our study the benign mucinous tumours showed positivity, the malignant mucinous tumours were negative.

Mesothelin is also shed like many other cell membrane proteins. A 42 to $44 \mathrm{kDa}$ protein called soluble mesothelin/MPF-related (SMR) protein, is seen in sera of patients with ovarian carcinomas and malignant mesothelioma. An elevation in serum mesothelin in ovarian cancer patients (67\%) was reported by Hassan et al. In both malignant mesothelioma and ovarian carcinoma patients, serum mesothelin levels were more frequently increased in patients of those which had tumour expressing mesothelin by immunohistochemistry. (17) In another study by McIntosh et al, found combined testing of serum CA- 125 and mesothelin to be having more sensitivity than CA-125 alone in detecting epithelial ovarian cancer.(18) In another study done by Badgwell et al observed urine mesothelin level assessment to be of more sensitivity than serum mesothelin levels in diagnosing patients with early and late stage ovarian cancer. In their study elevated levels of urine mesothelin was observed in $77.6 \%$ of serous and $71 \%$ of mixed tumours, while none of the mucinous tumours showed increased mesothelin in the urine.(19)

Many studies done in the recent have suggested the role of mesothelin in cell survival, migration, invasion and tumour progression.(20) Tumour cells expressing mesothelin are found to increase IL6 production and hence cancer cell survival and proliferation. Mesothelin also protects the cancer cells from TNF $\alpha$ induced apoptosis by PI3K/AKT pathway stimulation. Mesothelin was also found to have role in tumour adhesion and metastasis based on evidence that it can bind to MUC-16 (Also known as CA-125) and mediate heterotypic cell adhesion, thereby aiding in the peritoneal implantation and metastasis of tumours.(21) In ovarian cancers, mesothelin induces MMP-7 secretion and enhances the migration and invasion of cancer cells and thereby further tumour progression.(22) Mesothelin is found to have a role in metastasis by inducing the expression of matrix metalloproteinases 7 and 9.(23)

The current study revealed diffuse mesothelin expression in tumour tissue of serous carcinomas irrespective of the grade. The cases of residual tumours following post chemotherapy also were mesothelin positive. The prognostic significance of mesothelin studied in one study revealed that in high-grade ovarian carcinomas, diffuse mesothelin expression ( $>50 \%)$ significantly correlated with better survival in patients with advanced stage disease. In contrary, few studies have reported an increased mesothelin expression was associated with chemoresistance of the tumours. It was conferred further that mesothelin expressing cancer cells can resist the cytotoxic drug induced apoptosis.(24)

The primary treatment modalities of malignant epithelial ovarian tumours include surgical tumour resection followed by chemotherapy. The adjuvant chemotherapy, i.e. consisting of a platinum compound (Cisplatin/Carboplatin) is the standard therapy in use. However, $50 \%-70 \%$ of patients show relapse.(24) Hence, the development of new drugs and therapeutic strategies for the management of these patients is definitely in need to improve the survival and prognosis of patients. Tumour-specific antibody-based therapies using mesothelin as targets have been under study. $(21,23)$

\section{CONCLUSIONS}

In the present study and also other studies, it is found that mesothelin is highly expressed in serous carcinomas irrespective of the grade and also in post chemotherapy tumours. This suggests that therapy using mesothelin as target may be of possible use in malignant serous tumours. However, larger studies regarding the same along with clinical approach are needed to establish the role in management of epithelial ovarian cancer.

\section{REFERENCES}

1. Ferlay J, Soerjomataram I, Dikshit R, et al. Cancer incidence and mortality worldwide: sources, methods and major patterns in GLOBOCAN 2012. Int J Cancer 2015;136(5):E359-86

2. Murthy NS, Shalini S, Suman G, et al. Changing trends in incidence of ovarian cancer- the Indian scenario. Asian Pac J Cancer Prev 2009;10(6):1025-30. 
3. Kurman RJ, Carcangiu ML, Herrington S, et al. Tumours of ovary. In: WHO classification of tumours of female reproductive organs. Lyon: international agency for research on cancer 2014.

4. Seidman DJ, Cho RK, Ronnett MB, et al. Surface epithelial tumors of the ovary. In: Kurman RJ, Ellenson LH, Ronnett BM (edr). Blaustein's pathology of the female genital tract. 6/E. New York. Springer 2011:680-701.

5. Abdel-Azeez HA, Labib HA, Sharaf SM, et al. HE4 and mesothelin: novel biomarkers of ovarian carcinoma in patients with pelvic masses. Asian Pac J Cancer Prev 2010;11(1):111-6.

6. American College of Obstetricians and Gynecologists Committee on Gynecologic Practice. Committee opinion No. 477: the role of the obstetrician-gynecologist in the early detection of epithelial ovarian cancer. Obstet Gynecol 2011;117(3):742-6.

7. Felder M, Kapur A, Gonzalez-Bosquet J, et al. MUC16 (CA125): tumor biomarker to cancer therapy, a work in progress. Mol Cancer 2014;13(1):129.

8. Huang CY, Cheng WF, Lee CN, et al. Serum mesothelin in epithelial ovarian carcinoma: a new screening marker and prognostic factor. Anticancer Res 2006;26(6C):4721-8.

9. Mills GB, Bast RC, Srivastava S. Future for ovarian cancer screening: novel markers from emerging technologies of transcriptional profiling and proteomics. J Natl Cancer Inst 2001;93(19):1437-9.

10. Einama T, Homma S, Kamachi H, et al. Luminal membrane expression of mesothelin is a prominent poor prognostic factor for gastric cancer. Br J Cancer 2012;107(1):137-42.

11. Yen MJ, Hsu CY, Mao TL, et al. Diffuse mesothelin expression correlates with prolonged patient survival in ovarian serous carcinoma. Clin Cancer Res 2006; 12(3Pt1):827-31.

12. Muminova ZE, Strong TV, Shaw DR. Characterization of human mesothelin transcripts in ovarian and pancreatic cancer. BMC Cancer 2004;4(19):1471-2407.

13. Kurman RJ, Shihle M. The origin and pathogenesis of epithelial ovarian cancer: a proposed unifying theory. Am J Surg Pathol 2010;34(3):433-43.

14. Furuya M. Ovarian cancer stroma: pathophysiology and the roles in cancer development. Cancers 2012;4(3): 701-24.
15. Frierson HF, Moskaluk CA, Powell SM, et al. Large-scale molecular and tissue microarray analysis of mesothelin expression in common human carcinomas. Hum Pathol 2003;34(6):605-9.

16. Ornandez NG. Application of mesothelin immunostaining in tumor diagnosis. Am J Surg Pathol 2003;27(11):141828.

17. Hassan R, Remaley AT, Sampson ML, et al. Detection and quantitation of serum mesothelin, a tumor marker for patients with mesothelioma and ovarian cancer. Clin Cancer Res 2006;12(2):447-53.

18. McIntosh MW, Drescher C, Karlan B, et al. Combining CA125 and SMR serum markers for diagnosis and early detection of ovarian carcinoma. Gynecol Oncol 2004;95(1):9-15.

19. Badgwell $\mathrm{D}, \mathrm{Lu} \mathrm{Z}$, Cole $\mathrm{L}$, et al. Urinary mesothelin provides greater sensitivity for early stage ovarian cancer than serum mesothelin, urinary hCG free beta subunit and urinary hCG beta core fragment. Gynecol Oncol 2007;106(3):490-7.

20. Chen SH, Hung WC, Wang P, et al. Mesothelin binding to CA125/MUC16 promotes pancreatic cancer cell motility and invasion via MMP-7 activation. Sci Rep 2013;3:1870.

21. Tang Z, Qian M, Ho M. The role of mesothelin in tumor progression and targeted therapy. Anticancer Agents in Med Chem 2013;13(2):276-80.

22. Chang MC, Chen CA, Chen PJ, et al. Mesothelin enhances invasion of ovarian cancer by inducing MMP-7 through MAPK/ERK and JNK pathways. Biochem J 2012;442(2):293-302.

23. Golfier S, Kopitz C, Kahnert A, et al. Anetumab ravtansine: a novel mesothelin-targeting antibody-drug conjugate cures tumors with heterogeneous target expression favoured by bystander effect. Mol Cancer Ther 2014;13(6):1537-48.

24. Cheng W, Huang $\mathrm{C}$, Chang $\mathrm{M}$, et al. High mesothelin correlates with chemoresistance and poor survival in epithelial ovarian carcinoma. Br J Cancer 2009; 100(7): 1144-53. 